\title{
Robustness of Pseudomonas putida KT2440 as a host for ethanol biosynthesis
}

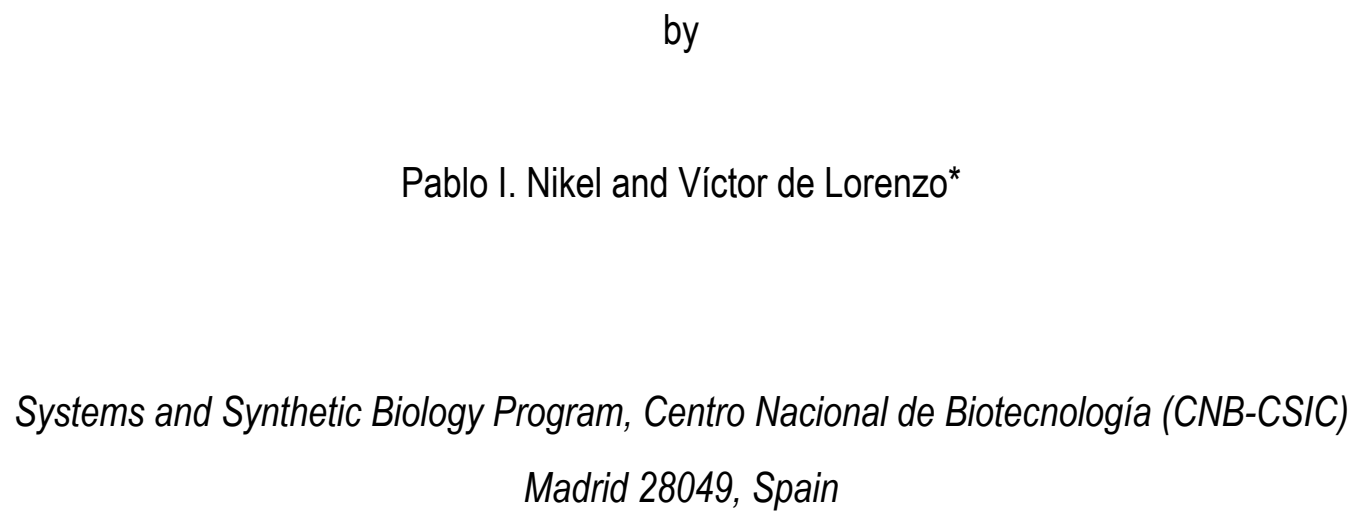




\section{Abstract}

2

3 Expansion of the burgeoning biofuels agenda involves not only the design of suitable genetic and

4 metabolic devices but also their deployment into suitable hosts that can endure the stress brought 5 about by the products themselves. The microorganisms easiest to genetically manipulate for 6 these endeavours (e.g., Escherichia coli) are often afflicted by an undesirable sensitivity to the 7 very product that they are engineered to synthesize. In this context, we have examined the 8 resistance to the stress arising from ethanol synthesis and/or its addition to cultures of 9 recombinant Pseudomonas putida, using as a benchmark the same trait in an E. coli strain. To 10 this end, ethanologenic strains of these two species were constructed by functionally expressing $11 p d c$ (pyruvate decarboxylase) and adhB (alcohol dehydrogenase) from Zymomonas mobilis.

12 Recombinants were compared under anoxic conditions as ethanol producers, and cell survival, 13 stress resistance, and phenotypic stability were quantified in each case. P. putida consistently outperformed $E$. coli in every ethanol tolerance test conducted - whether the alcohol was produced endogenously or added exogenously. These results highlight the value of such bacterium as a microbial cell factory for the production of biofuels owing to its naturally preevolved ability to withstand different kinds of chemical stresses.

\section{Introduction}

Ongoing efforts to manipulate microorganisms for the production of valuable biochemicals mostly revolve around plugging-in and -out genes needed for their synthesis in a few bacterial chasses [1]. An interesting example that profits from Synthetic Biology tools and strategies is biofuel synthesis [2-5]. The production of fuel substitutes such as bioalcohols and biodiesel from renewable resources has gained significant attention over the last decades because of the continuously rising energy and oil prices and environmental concerns $[6,7]$. So far, biofuel production has mainly focused on ethanol (EtOH) [8-11], which currently comprises $>90 \%$ of the total bioalcohols consumed in the United States [12]. The seminal work of Ingram and collaborators, who originally cloned the genes needed for EtOH biosynthesis from Zymomonas mobilis and expressed them in Escherichia coli [13-17], paved the way towards the construction 
1 of efficient microbial cell factories for bioalcohol synthesis with a suite of desirable industrial traits.

2 Other attempts within the increasingly explored biofuels production field also include butanol [18-

3 20], and, most recently, gasoline (i.e., triacylglycerides esters) [21]. In the recent years, the

4 combination of model-based predictions and high-throughput technologies has further improved

5 the design of efficient biocatalysts for biofuels production by investigating physiological traits at

6 the systems level - thus extending metabolic engineering strategies far beyond the mere cloning

7 and expression of a limited number of structural genes. Yet, several hurdles have to be

8 considered and solved before bioalcohol production en masse becomes technically feasible and

9 economically viable - some of these problems being caused by the very nature of the product at

10 stake.

12 One of the major challenges in the bulk production of EtOH (mainly from biomass) is the effect of 13 inhibitory compounds generated during the thermo-chemical pre-treatment of the substrate [22]. Inhibitory chemical species of this sort, such as weak acids, furans, and phenolic compounds, are very toxic to the fermenting microorganisms and their presence seriously compromises the final $\mathrm{EtOH}$ yield and overall productivity during the fermentation of lignocellulosic hydrolysates [23-25]. Along the line, tolerance to $\mathrm{EtOH}$ itself is another desirable trait in an efficient biocatalyst [16, 26, 27]. EtOH causes several changes at the level of the cell membrane [28, 29], ultimately altering

19 its physical structure and giving rise to highly-damaging reactive oxygen species (ROS) [30, 31].

20 Thus, two sources of alcohol-related stresses can be identified in ethanologenic microorganisms, 21 namely, [i] the endogenous stress caused by the intracellular synthesis of $\mathrm{EtOH}$, and [ii] the 22 exogenous stress produced by alcohol accumulation in the culture medium. Such insults can 23 ultimately translate in DNA damage (which elicits the SOS response), heat shock, acid stress 24 response, starvation response, and the envelope stress response. We have argued that 25 processes that involve contact or production of chemical stressors may benefit from adopting 26 whole-cell catalysts based on environmental bacteria that thrive in niches with a history of 27 exposure to xenobiotic and recalcitrant compounds [32]. Among them, Pseudomonas putida comes into view as an appealing host for EtOH synthesis considering its [i] intrinsically high resistance to different stressors (including several solvents), [ii] amenability to genetic 30 manipulation, [iii] ability to grow very fast on simple substrates, and [iv] GRAS (i.e., generally recognised as safe) credentials of some strains of this species (e.g., KT2440) [33-35]. 
1 In this work, we have examined the value of metabolically-engineered derivatives of $P$. putida 2 strain KT2440 as active agents for bioalcohol production, that can be potentially used in 3 bioprocesses conducted in the presence of high $\mathrm{EtOH}$ concentrations. To this end, the genes

4 needed to activate an EtOH synthesis pathway in $P$. putida were recruited from Z. mobilis, and 5 the performance of the resulting strain as a microbial cell factory for biofuel synthesis was 6 thoroughly tested. Quantification of ROS production, overall fitness, extracellular metabolome 7 patterns, cell growth and survival in the presence of ethanol, as well as the phenotypic stability 8 among the ethanologenic strains, accredited the worth of $P$. putida as a promising host for 9 engineering bioalcohol production.

\section{Material and Methods}

Bacterial strains, culture conditions, and general techniques

Bacterial strains and plasmids used in this study are listed in Table 1. E. coli and P. putida strains were routinely grown at $37^{\circ} \mathrm{C}$ and $30^{\circ} \mathrm{C}$, respectively, in complex $\mathrm{LB}$ medium under oxic conditions (i.e., in 125-ml Erlenmeyer flasks containing medium up to one-fifth of their nominal volume with agitation at $170 \mathrm{rpm})$. E. coli $\mathrm{DH} 5 \alpha$ and $\mathrm{CC} 118 \lambda$ pir were used for routine cloning procedures and plasmid maintenance and mating into $P$. putida. Recombinant $E$. coli and $P$. putida strains were grown in M9E medium, a modified culture medium based on M9. M9E medium contained $6 \mathrm{~g} \mathrm{l}^{-1} \mathrm{Na}_{2} \mathrm{HPO}_{4}, 3 \mathrm{~g} \mathrm{l}^{-1} \mathrm{KH}_{2} \mathrm{PO}_{4}, 1.4 \mathrm{~g} \mathrm{l}^{-1}\left(\mathrm{NH}_{4}\right)_{2} \mathrm{SO}_{4}, 0.5 \mathrm{~g} \mathrm{l}^{-1} \mathrm{NaCl}, 0.2 \mathrm{~g} \mathrm{l}^{-1}$ $\mathrm{MgSO}_{4} \cdot 7 \mathrm{H}_{2} \mathrm{O}, 5 \mathrm{mg} \mathrm{l}^{-1}$ thiamine $\cdot \mathrm{HCl}, 5 \mathrm{~g} \mathrm{l}^{-1}$ yeast extract, and $2.5 \mathrm{ml} \mathrm{l}^{-1}$ of a trace elements solution [36, 37]. Glucose was added as the sole carbon source to all experiments at $20 \mathrm{~g} \mathrm{l}^{-1}$.

24 Anoxic incubations were carried out in glass vials with teflon-stoppered metallic screw caps 25 (Sigma-Aldrich Co., St. Louis, MO, USA) essentially as previously described by Nikel and de Lorenzo [37]. Briefly, the biomass from cultures previously grown under oxic conditions to midexponential phase was concentrated by centrifugation ( $15 \mathrm{~min}$ at $4,000 \times g$ and $4^{\circ} \mathrm{C}$ ), washed once with cold saline $\left(9 \mathrm{~g} \mathrm{l}^{-1} \mathrm{NaCl}\right)$, and finally re-suspended in the adequate volume of $\mathrm{M} 9 \mathrm{E}$ medium. Fresh culture medium was inoculated at an optical density measured at $600 \mathrm{~nm}\left(\mathrm{OD}_{600}\right)$

30 of ca. 2. Growth was estimated by measuring the $\mathrm{OD}_{600}$ of appropriately diluted broth samples using an Ultrospec 3000 pro UVNisible Spectrophotometer (GE Healthcare Bio-Sciences Corp., 
1 Piscataway, NJ, USA). All solid media contained $15 \mathrm{~g} \mathrm{l}^{-1}$ agar and kanamycin $\left(\mathrm{Km}, 50 \mu \mathrm{g} \mathrm{ml}^{-1}\right)$, or

2 chloramphenicol $\left(30 \mu \mathrm{g} \mathrm{ml}^{-1}\right)$, were added to the culture media, when appropriate, as filter-

3 sterilised solutions. Isopropyl- $\beta$-D-thiogalactopyranoside (IPTG) was added at $2.5 \mathrm{mM}$ to induce

4 the expression of genes under the control of LaclQ/P trr. Plasmids were transferred into $P$. putida

$5 \quad$ KT2440 and its derivatives using the filter mating procedure described in detail by de Lorenzo

6 and Timmis [38]. EtOH concentration in culture supernatants, as well as the presence of other

7 fermentation metabolites (acetate, lactate, formate, and succinate), was determined in selected

8 samples using enzymatic kits (R-Biopharm AG, Darmstadt, Germany) as per the manufacturer's

9 instructions.

Alcohol tolerance assays and survival and plasmid stability

13 Colony forming units (CFUs) were counted after $6 \mathrm{~h}$ of solvent exposure at the concentrations indicated in the text to assess cellular fitness under $\mathrm{EtOH}$ stress. Cultures were serially diluted in 10-fold steps in LB medium containing no antibiotics. The dilution level was estimated based on $\mathrm{OD}_{600}$ measurements of the samples, and $50 \mu \mathrm{l}$ of the final dilution was then plated on LB agar with and without Km. After plating, CFUs were measured after 18 to $24 \mathrm{~h}$ of growth at either $37^{\circ} \mathrm{C}$ or $30^{\circ} \mathrm{C}$. This assay served as a measure of potential industrial use because it is a direct evaluation of recombinant cells that are still biologically active during solvent exposure [27]. At the same time, plasmid segregational stability was estimated by comparing CFUs in plates with and without $\mathrm{Km}$ from samples withdrawn from the anoxic incubation experiments.

Quantification of ROS in bulk cultures

25 Strains were incubated in M9E medium containing $0 \%, 0.5 \%, 1 \%, 1.5 \%$, and $5 \%$ (v/v) EtOH for 6

26 h. Aliquots of $100 \mu \mathrm{l}$ of pre-cultured strains grown as described in the preceding section were each re-suspended in $5 \mathrm{ml} \mathrm{M9E}$ medium, and $140 \mu \mathrm{l}$ of each diluted sample was transferred to a 28 96-well microtiter plate (clear-bottom, black polypropylene 96-well plates; Nunc A/S, Roskilde, 29 Denmark) followed by incubation at $30^{\circ} \mathrm{C}$ or $37^{\circ} \mathrm{C}$ for $30 \mathrm{~min}$. All samples were then added with $3010 \mu \mathrm{l}$ of $25 \mathrm{mM} 5$-(and-6)-carboxy-2',7'-dichlorodihydrofluorescein diacetate (carboxy- $\mathrm{H}_{2} \mathrm{DCFDA}$; Invitrogen Co., Carlsbad, CA, USA), carefully mixed, and statically incubated for $15 \mathrm{~min}$ in the 
1 dark $[39,40] . \mathrm{OD}_{600}$ values and fluorescence excitation/emission signals at $488 / 535 \mathrm{~nm}$ in each

2 sample were measured in quadruplicate in a SpectraMax Plus ${ }^{384}$ microplate reader (Molecular

3 Devices, Sunnyvale, CA, USA). Tert-butyl hydroperoxide (Sigma-Aldrich Co.), a known stressor

4 that produces intracellular $\mathrm{H}_{2} \mathrm{O}_{2}$, was added to some experiments as a positive control for the

5 ROS assay. These control experiments were prepared with the strains cultured without EtOH and

6 treated as above except for an initial $30 \mathrm{~min}$ incubation in the presence of $10 \mu \mathrm{l}$ of $5.5 \mathrm{M}$ tert-butyl

7 hydroperoxide.

9 Phenotypic stability of recombinant strains

11 Mixtures of $p$-rosaniline and $\mathrm{NaHSO}_{3}$ are often referred to as the Schiff's reagent and have been 12 widely used to detect aldehydes. Conway et al. [15] have incorporated these components into a 13 relatively non-toxic solid medium which can be used to easily identify clones expressing enzymes that produce aldehydes. Aldehyde indicator plates were set by promptly adding $8 \mathrm{ml}$ of a freshlyprepared p-rosaniline solution [2.5 mg ml-1 in 95\% (v/v) ethanol] and $100 \mathrm{mg}$ of $\mathrm{NaHSO}_{3}$ to 400 $\mathrm{ml}$ batches of pre-cooled (ca. $\left.45^{\circ} \mathrm{C}\right) \mathrm{LB}$ agar, previously amended with $0.5 \%(\mathrm{v} / \mathrm{v})$ ethanol, $10 \mathrm{~g} \mathrm{l}^{-1}$ glucose, and $2.5 \mathrm{mM}$ IPTG. Most of the dye is immediately converted to the leuco form by reaction with $\mathrm{NaHSO}_{3}$ to produce a rose-colored medium that was dispensed into Petri dishes.

19 Cells, anoxically incubated for $24 \mathrm{~h}, 48 \mathrm{~h}$, and $96 \mathrm{~h}$, were spread onto these plates and incubated at the appropriate temperature for 4-6 h. Magenta-coloured colonies were considered positive

$21\left(\mathrm{AdhB}^{+}\right)$, and alcohol dehydrogenase activity was further confirmed in selected clones through a 22 direct spectrophotometric assay by measuring the acetaldehyde-dependent oxidation of NADH (see details below). Fresh indicator plates were prepared no more than 2 days before use and stored at room temperature thereafter.

Preparation of cell-free extracts and in vitro determination of enzyme activities

28 Cell-free extracts were obtained from cells incubated anoxically and harvested by centrifugation from an appropriate culture volume at $4,000 \times g$ at $4^{\circ} \mathrm{C}$ for $10 \mathrm{~min}$. Pellets were suspended in 1

30 volume of $10 \mathrm{mM}$ sodium phosphate buffer $(\mathrm{pH}=7.5$, previously refrigerated) containing $0.1 \mathrm{M} 2-$ mercaptoEtOH and centrifuged again as described above. Cells were finally re-suspended in 0.3- 
10.5 volume of the same buffer and sonicated intermittently for $5 \mathrm{~min}$ in an ice bath. Sonicated 2 cells were centrifuged at $7,500 \times g$ at $4^{\circ} \mathrm{C}$ for $30 \mathrm{~min}$ to remove cell debris and to reduce the $3 \mathrm{NADH} / \mathrm{NAD}^{+}$background in the lysate. Total protein concentration in cell extracts was measured

4 by the Bradford method [41] using a commercially available kit from BioRad Laboratories, Inc. 5 (Hercules, CA, USA), with crystalline bovine serum albumin as the standard. Pdc catalyses the 6 decarboxylation of pyruvate to acetaldehyde. The assay is an indirect method in which the 7 conversion is linked to the activity of alcohol dehydrogenase, that is supplied in excess and 8 effectively converts acetaldehyde into $\mathrm{NAD}^{+}$and ethanol $[42,43]$. The assay mixture (1 $\mathrm{ml}$ final 9 volume) contained $50 \mathrm{mM}$ 2-( $\mathrm{N}$-morpholino)ethanesulfonic acid $\mathrm{KOH}(\mathrm{pH}=6.5), 5 \mathrm{mM} \mathrm{MgCl} 2,0.1$ $10 \mathrm{mM}$ thiamine pyrophosphate, $0.15 \mathrm{mM} \mathrm{NADH}, 10$ units $\mathrm{ml}^{-1}$ alcohol dehydrogenase (from 11 Saccharomyces cerevisiae, Sigma-Aldrich $\mathrm{Co}_{\text {.). }}$, and $5 \mathrm{mM}$ pyruvate. AdhB activity was assayed 12 by measuring the ethanol-dependent reduction of $\operatorname{NAD}^{+}[15,44]$. The assay mixture $(1 \mathrm{ml})$ 13 contained $50 \mathrm{mM}$ sodium phosphate buffer $(\mathrm{pH}=6.5), 350 \mathrm{mM}$ ethanol, and $10 \mathrm{mM} \mathrm{NAD}$. In both Pdc and AdhB assays, the cell-free extract was added to the reaction mixture, and the rate of change of absorption at $340 \mathrm{~nm}$ was recorded at $30^{\circ} \mathrm{C}$. An extinction coefficient $\left(\varepsilon_{\mathrm{NADH}}\right)$ of 6.22 $\mathrm{mM}^{-1} \mathrm{~cm}^{-1}$, representing the difference between the extinction coefficients of $\mathrm{NADH}$ and $\mathrm{NAD}^{+}$, was used in both assays. One unit of activity was defined as the quantity of enzyme that 18 catalysed the formation of $1 \mu \mathrm{mol}$ product in $1 \mathrm{~min}$ at $30^{\circ} \mathrm{C}$.

Statistical analysis

Data were statistically treated with an unpaired $t$ test, and $95 \%$ or $99 \%$ confidence intervals for each parameter were calculated to demonstrate a statistically significant difference in means among the experimental samples.

\section{Results and Discussion}

Rationale for the construction of ethanologenic $P$. putida strains

30 The starting point of this work was the examination of the native pathways through which E. coli naturally ferments sugars to a mixture of EtOH and organic acids under anoxic conditions (Fig. 1). 
$1 \mathrm{EtOH}$ is produced from pyruvate through the activity of pyruvate-formate lyase (Pfl) [45], which 2 replaces (at least partially) the $\mathrm{NAD}^{+}$-dependent pyruvate dehydrogenase complex in the 3 absence of oxygen [46]. This fermentation pathway is, however, unbalanced, because one NADH

4 is generated for each pyruvate molecule arising from sugars, and two NADH molecules are 5 required to convert pyruvate into ethanol. E. coli balances this biochemical process by also 6 producing acetate, lactate, and succinate as co-products of the fermentative metabolism [45, 47]. 7 Unlike Enterobacteria, P. putida exclusively uses the Entner-Doudoroff pathway (Fig. 1) for oxic 8 hexose processing $[48,49]$. A side effect of this situation is the generation of one NADPH and one NADH per glucose consumed, instead of the two NADH molecules per glucose consumed

10 through the Embden-Meyerhof-Parnas pathway [50]. On the other hand, yeast and Z. mobilis are deemed homoethanologenic fermentative microorganisms because they convert pyruvate to $\mathrm{EtOH}$ almost stoichiometrically by means of pyruvate decarboxylase (Pdc), which only consumes one NADH for each EtOH produced (Fig. 2A) [51, 52]. Since the native alcohol dehydrogenase activity of $E$. coli is not sufficient to achieve high EtOH yields, Ingram et al. $[13,15]$ originally isolated adhB (encoding alcohol dehydrogenase II) from a genomic library of Z. mobilis to complement the Pdc activity in a two-step biochemical conversion of pyruvate into ethanol. As a consequence, $E$. coli transformed with a plasmid expressing $p d c$ and adhB mostly produced $\mathrm{EtOH}$ as the main fermentation metabolite [13]. Building on this background, we asked what could be the physiological impact of entering a homoethanologenic fermentation pathway in a metabolic network that operate different catabolic pathways as E. coli and P. putida do. To tackle this issue, we constructed a synthetic operon in which $p d c$ and adhB from Z. mobilis (Fig. 2A) were co-expressed as a single transcriptional unit from the IPTG-inducible Ptrc $_{\text {tr }}$ promoter (Fig. 2B). The vector carrying these genes, termed pS234ET (Table 1), was introduced in parallel into the wild-type hosts $E$. coli BW25113 and P. putida KT2440. This operation resulted in EtOH formation $(<2 \mathrm{mM})$ by $E$. coli recombinants even under oxic growth conditions and in non-induced cultures. Under the same conditions, no detectable EtOH was detected in $P$. putida recombinants.

When cells of the recombinants were shifted to anoxic conditions in tightly sealed glass vials, both bacteria were able to produce $\mathrm{EtOH}$ from glucose as detected in culture supernatants after $24 \mathrm{~h}$ (Fig. 2C). Under these non-optimised conditions, E. coli and P. putida performed almost equally as engineered ethanologenic bacteria, as the final $\mathrm{EtOH}$ titre reached $29.1 \pm 3.5 \mathrm{mM}$ and 
$123.8 \pm 6.3 \mathrm{mM}$, respectively. Some EtOH was also detected in the absence of IPTG in the strains 2 bearing pS234ET, its concentration attaining $32 \%$ and $54 \%$ of that observed in induced cultures 3 of $E$. coli and $P$. putida, respectively. These figures point to a higher leakiness of the $L a c \mid Q / P_{t r c}$ 4 expression system in pseudomonads as compared to its behaviour in enterobacteria [53, 54]. $E$. coli BW25113 carrying the empty pSEVA234 vector still produced a small but significant amount of alcohol, likely as result of the action of the native $\operatorname{AdhE}(p<0.05$, as compared with $P$. putida cultures). As previously noted by Ingram et al. [13] and Clark [45], EtOH represented $<5 \%$ of the total fermentation metabolites produced by $E$. coli when grown on glucose.

Other fermentation by-products (besides ethanol) were quantified in culture supernatants of the strains under study. While the extracellular fermentation metabolome of $P$. putida was entirely restricted to ethanol, ethanologenic E. coli strains also produced acetate, lactate, succinate, and formate as co-products of anoxic glucose utilization (Table 2). Among these metabolites, acetate prevailed as the main product of glucose fermentation by $E$. coli BW25113/pS234ET. As expected, over-expression of $p d c$-adhB $B^{\text {. mobilis }}$ determined a decrease in the formation of all the remaining fermentative products, considering both [i] the draining of pyruvate away from the native fermentation pathways to be re-routed into $\mathrm{EtOH}$ synthesis, and [ii] the likely dearth of $\mathrm{NADH}$ (used in the AdhBZ. mobilis-dependent reduction of acetaldehyde), a co-factor used by LdhA (catalyzing the formation of lactate), the reductive branch of the tricarboxylic acid cycle (which generates succinate), and AdhE (the extant alcohol dehydrogenase of $E$. coli, which might contribute to $\mathrm{EtOH}$ formation in the recombinants to some extent) $[47,55]$. Taken together, these results accredited the performance of a $P$. putida-based process for EtOH synthesis. In addition, the metabolome of either ethanologenic strain revealed an improved conversion of pyruvate to EtOH by P. putida (through the Entner-Doudoroff route, Fig. 1) as compared to the spill of byproducts typically observed in the $E$. coli counterpart used as a reference.

EtOH synthesis vs. cell survival

The next question was whether the natural tolerance to organic solvents of $P$. putida could be also beneficial for its performance as an ethanol-producing microbial cell factory. Specifically: does $\mathrm{EtOH}$ produced by the recombinant strains cause stress to the cells? To answer this 
1 question, we performed a simple survival test of the strains by plating dilutions of the cultures

2 throughout the anoxic incubation period onto LB plates and scoring CFUs after $24 \mathrm{~h}$ (Fig. 3).

$3 \mathrm{EtOH}$ synthesis was also assayed in these cultures. As the anoxic incubation proceeded, the

4 EtOH concentration in the supernatant increased for both bacterial hosts. The pattern of cell

5 survival for each strain was however very different. In E. coli BW25113/pS234ET, EtOH

6 accumulation increased linearly with time, but survival of bacteria in the same culture followed a

7 pronounced decline (Fig. 3A). In contrast, survival of $P$. putida was not affected at all by the

8 presence of endogenously produced $\mathrm{EtOH}$ (Fig. 3B). At the highest alcohol concentration, the

9 survival was in fact 1.2-fold higher than the maximal observed for the reference ethanologenic $E$.

10 coli strain $(p<0.05)$. Moreover, the $P$. putida recombinant expressing $p d c$-adh $B^{Z}$. mobilis had higher

11 anoxic survival values (i.e., > 100\% for all data points) than the control strain carrying the empty

12 plasmid. As described previously, $N A D^{+}$recycling through the activity of $A d h B^{2}$. mobilis represents a

13 way to re-oxidize excess reducing power, thereby allowing for enhanced fitness of $P$. putida

14 KT2440 in the absence of oxygen [37]. Taken together, these results reveal a superior tolerance

15 of $P$. putida to the endogenous stress produced by EtOH production (especially at $24 \mathrm{~h}$, at which

16 point the level of alcohol in the medium was comparable to the reference $E$. coli strain).

$P$. putida is highly resistant to the oxidative stress caused by endogenous EtOH production

20 One of the primary effects of alcohols on bacteria is perturbation of cell membrane function, 21 which is typically translated into generation of ROS [30, 40, 56, 57]. Production of these agents is 22 not entirely circumscribed to oxic conditions [58], as cells thriving in micro-oxic environments can produce ROS as the respiratory chain is still partially active [59]. We hypothesized that the enhanced tolerance of $P$. putida to endogenously-produced EtOH could be traced to a decrease 25 in the ensuing production of such ROS. To ascertain this question, the level of stress imposed by endogenous $\mathrm{EtOH}$ was directly quantified in the recombinants by using the fluorescent probe carboxy- $\mathrm{H}_{2}$ DCFDA (Fig. $3 \mathrm{C}$ ). Carboxy- $\mathrm{H}_{2}$ DCFDA is a non-fluorescent molecule that can be readily converted into a green-fluorescent form when the acetate groups are removed by intracellular esterases, followed by oxidation (via the activity of ROS) occurring within the cell. As

30 shown in Fig. 3C, the amount of ROS detected in EtOH-producing $P$. putida recombinants was ca. half that observed for $E$. coli, which inversely correlated with survival values. This is consistent 
1 with the notion that ability to form CFUs when transferred into fresh medium is plausibly related to

2 endurance to the stress caused by the alcohol. Note, however, that levels of EtOH produced by

3 the recombinants under these culture conditions consistently remained below $2.5 \mathrm{~g} \mathrm{l}^{-1}$ [i.e., ca.

$40.32 \%(\mathrm{v} / \mathrm{v})]$ which is still a very low concentration if one thinks on a large-scale production

5 process. How far up can $P$. putida go into an authentic industrial EtOH production setup, where

6 the target levels of this metabolite cannot go below $1 \%(\mathrm{v} / \mathrm{v})$ ?

7

8 Resistance to endogenous vs. exogenous $\mathrm{EtOH}$

10 The results above prompted the question of whether resistance to exogenously added $\mathrm{EtOH}$ might be also different among the strains. In a typical fed-batch process, products accumulate over time. In such an industrial scenario applied to bioalcohol formation, alcohol concentrations can reach as high as 3\% (v/v) [8]. To investigate these possibilities, we examined survival and stress related to the addition of $\mathrm{EtOH}$ at different concentrations to the growth culture. As shown in Fig. 4, E. coli BW25113/pS234ET was much more sensitive to EtOH addition than $P$. putida KT2440/pS234ET for all the concentrations tested within the range $0.5 \%$ to $5 \%(\mathrm{v} / \mathrm{v})$. As the percentage of added alcohol increased, the survival of all the strains trended downwards - more pronouncedly so in the case of the reference $E$. coli strain: at the highest concentration assayed, the survival of $P$. putida recombinants was $\sim 2.2$-fold higher $(p<0.01)$. Following the same rationale above for the endogenous production of ethanol, we entertained that the stress endurance of the $P$. putida biocatalyst should be higher than $E$. coli, a trait which would be finally reflected in larger CFUs counts. To evaluate this possibility, we measured the oxidative status of the recombinants as explained above (Fig. 5). As expected, addition of EtOH elicited an increase of the ROS levels that paralleled the final alcohol concentration. The stressful effects of this metabolite were more pronounced in the reference $E$. coli strain (as reflected in an 1.7-fold higher carboxy- $\mathrm{H}_{2}$ DCFDA signal; Fig. $5 \mathrm{~A}$ ) as compared to $P$. putida (Fig. $5 \mathrm{C}$ ) when challenged with $5 \%$ $(v / v) \mathrm{EtOH}(p<0.05)$. This behaviour was not limited to ethanol: addition of tert-butyl hydroperoxide, which directly results in formation of $\mathrm{H}_{2} \mathrm{O}_{2}$, produced a more dramatic effect in $E$. coli in terms of ROS generation (Fig. 5B and 5D). In this case, the ROS level was 1.5-fold higher

30 in the enterobacterial ethanologen, mirroring the differences observed when assessing the 
1 ethanol-dependent formation of ROS. Again, there was a direct link between ROS generation and

2 cell survival scores, that correlated well throughout the concentrations assayed.

$4 \quad$ P. putida shows enhanced activity of the heterologous enzymes needed for EtOH production

6 As the stress tolerance of $P$. putida ethanologens was higher than that of $E$. coli recombinants

7 under all the conditions tested, we wondered whether the biocatalytic vigour of the cells shows

8 any difference in the presence of the final product of the biotransformation. In a control

9 experiment, the specific enzyme activities of $\mathrm{Pdc}$ and $\mathrm{AdhB}$ were quantified in cell-free extracts of

10 the strains at stake (Table 3) after an anoxic 24-h incubation period. Surprisingly, no significant

11 differences were observed between the two strains bearing pS234ET. A very small, but

12 significant background level of alcohol dehydrogenase activity was detected in both $E$. coli and $P$.

13 putida carrying the empty pSEVA234 vector (data not shown), revealing that either the native

14 AdhE (in E. coli) [60] or one of the several putative alcohol dehydrogenases (in P. putida) [61, 62]

15 contributed to the overall activity detected. In contrast, no pyruvate decarboxylase was present in

16 the control strains. When EtOH was added at $1 \%$ and $5 \%(\mathrm{v} / \mathrm{v})$, the specific Pdc $\mathrm{Z}$. mobilis activity

17 was diminished in E. coli BW25113/pS234ET by $33 \%$ and $62 \%$, respectively $(p<0.05)$. Likewise,

18 the specific AdhBz. mobilis activity dropped to $31 \%$ and $80 \%$, respectively, of that observed in the

19 absence of any added alcohol $(p<0.05)$. When the same enzymes were assayed in $P$. putida

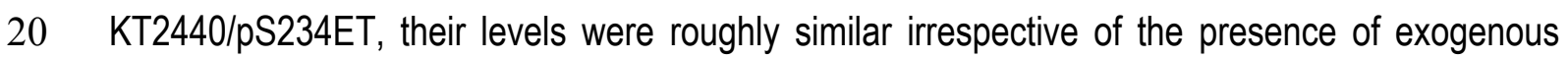

$21 \mathrm{EtOH}$ in the culture medium. Addition of $1 \%(\mathrm{v} / \mathrm{v}) \mathrm{EtOH}$ did not translate into any significant

22 difference of neither Pdc zobilis nor AdhBZ. mobilis activities. At the highest alcohol concentration, on

23 the contrary, both enzymatic activities were diminished ex aequo by ca. $20 \%$. These results

24 endorsed the vigour of $P$. putida under all the conditions tested, especially in the presence of an

25 external stressor - an important advantage in bioprocesses in which the final product is toxic to 26 the producing cells.

Phenotypic stability of ethanologens after extended anoxic incubation

30 As the enzymatic activities from which $\mathrm{EtOH}$ stem in the recombinants were subjected to

significant fluctuations as the external EtOH concentration increased, it was also relevant to 
1 assess whether the recombinants could maintain their catalytic properties after prolonged anoxic 2 incubation - a condition pertinent to industrial setups, in which EtOH is to be accumulated over 3 time. In this context, we assayed the gross alcohol dehydrogenase activity of the recombinants

4 after 1, 2, and 4 days of incubation by means of a colorimetric test that allowed the visualization 5 of positive clones as bright pink colonies onto aldehyde indicator plates. A representative 6 example of the results obtained when plating the ethanologens onto these plates after 2 and 4

7 days is shown in Fig. $6 \mathrm{~A}$ and $6 \mathrm{~B}$. Visual inspection of the assay revealed that, while the reference 8 E. coli strain seemed to quickly lose the $\mathrm{AdhB}^{+}$phenotype (Fig. 6A), P. putida recombinants 9 displayed a high level of aldehyde formation when transferred onto indicator medium plates (Fig. 10 6B). By directly counting $\mathrm{AdhB}^{-}$and $\mathrm{AdhB}^{+}$colonies, the fraction of phenotypically stable clones was quantified (Fig. 6C). After $24 \mathrm{~h}$ of anoxic incubation, both strains almost completely retained

12 the alcohol-producing phenotype bestowed by pS234ET. Significant differences, however, were 13 observed at $48 \mathrm{~h}$ and $96 \mathrm{~h}$, as the fraction of $E$. coli $\mathrm{AdhB}^{+}$cells steadily decreased to reach $68.1 \% \pm 1.5 \%$. After the same time period, $>90 \%$ of the $P$. putida cells retained the $\mathrm{AdhB}^{+}$ phenotype $(p<0.01)$. Moreover, the specific AdhB activity was assayed in vitro for some of the clones that gave a positive signal in aldehyde-indicator plates, and the enzymatic activity levels were comparable to those reported in Table 3 in the absence of any added alcohol. The ethanolproducing phenotype was not completely related to plasmid loss, as observed in other ethanologens [63]. We assessed the fraction of $\mathrm{Km}^{\mathrm{R}}$ colonies in these cultures to estimate the segregational stability of pS234ET, and found that this parameter decreased slightly for $E$. coli, while it was maintained at $>87 \%$ in $P$. putida recombinants. However, E. coli retained $>80 \%$ of the ethanologenic plasmid after $96 \mathrm{~h}$, which does not suffice to explain the loss of catalytic activity. It is thus plausible that the differences observed arise from metabolic changes in the cells bearing pS234ET rather than the mere plasmid loss - again pointing to the superior metabolic robustness of $P$. putida.

\section{Conclusion}

The data presented above highlights the value of environmental bacteria that naturally thrive in 30 sites polluted with xenobiotic contaminants as hosts for the expression of heterologous biochemical routes involving toxic compounds [32, 34, 48, 64]. This situations stems from the fact 
1 that the evolutionary roadmap of such bacteria to degrade otherwise recalcitrant molecules can

2 occur only if the biological vessel of the process can endure high levels of endogenous metabolic

3 stress and physico-chemical insults. We argue that of hosts of this sort - like the $P$. putida strain

4 employed in this work, are pre-evolved biological recipients that Nature offers as optimal hosts for

5 biotechnological applications [34, 65]. The results above demonstrate the importance of stress

6 resistance and catalytic robustness in processes that produce biochemicals (e.g., biofuels) that

7 might act as stressors themselves, highlighting, at the same time, the choice of $P$. putida as a

8 potential host of reference for biocatalysis at an industrial scale.

\section{Acknowledgements}

This study was supported by the BIO Program of the Spanish Ministry of Economy and

13 Competitiveness, the ST-FLOW and ARIAYS Contracts of the EU, and the PROMT Project of the

14 CAM. PIN is a researcher from the Consejo Nacional de Investigaciones Científicas y Técnicas

15 (Argentina) and holds a Marie Curie Actions Program grant from the EC (ALLEGRO, UE-FP7-

16 PEOPLE-2011-IIF-300508). Authors declare no conflicts of interest.

\section{References}

[1] Danchin A. Scaling up synthetic biology: do not forget the chassis. FEBS Lett 2012;586:2129-37.

[2] Colin VL, Rodríguez A, Cristóbal HA. The role of synthetic biology in the design of microbial cell factories for biofuel production. J Biomed Biotechnol 2011;2011.

[3] Jang YS, Park JM, Choi S, Choi YJ, Seung DY, Cho JH, et al. Engineering of microorganisms for the production of biofuels and perspectives based on systems metabolic engineering approaches. Biotechnol Adv 2012;30:989-1000.

[4] Jarboe LR, Zhang X, Wang X, Moore JC, Shanmugam KT, Ingram LO. Metabolic engineering for production of biorenewable fuels and chemicals: contributions of synthetic biology. J Biomed Biotechnol 2010;2010:761042.

[5] Wen M, Bond-Watts BB, Chang MC. Production of advanced biofuels in engineered E. coli. Curr Opin Chem Biol 2013;17:472-9. 
1 [6] Li H, Cann AF, Liao JC. Biofuels: biomolecular engineering fundamentals and advances. $2 \quad$ Annu Rev Chem Biomol Eng 2010;1:19-36.

3 [7] Demain AL. Biosolutions to the energy problem. J Ind Microbiol Biotechnol 2009;36:3194

5 [8] Geddes CC, Nieves IU, Ingram LO. Advances in ethanol production. Curr Opin Biotechnol 6

[9] Vertès AA, Inui M, Yukawa H. Technological options for biological fuel ethanol. J Mol

[11] Clomburg JM, Gonzalez R. Biofuel production in Escherichia coli: the role of metabolic engineering and synthetic biology. Appl Microbiol Biotechnol 2010;86:419-34.

[12] Farrell AE, Plevin RJ, Turner BT, Jones AD, O'Hare M, Kammen DM. Ethanol can contribute to energy and environmental goals. Science 2006;311:506-8.

[13] Ingram LO, Conway T, Clark DP, Sewell GW, Preston JF. Genetic engineering of ethanol production in Escherichia coli. Appl Environ Microbiol 1987;53:2420-5.

[14] Ohta K, Beall DS, Mejia JP, Shanmugam KT, Ingram LO. Genetic improvement of Escherichia coli for ethanol production: chromosomal integration of Zymomonas mobilis genes encoding pyruvate decarboxylase and alcohol dehydrogenase II. Appl Environ Microbiol 1991;57:893-900.

[15] Conway T, Sewell GW, Osman YA, Ingram LO. Cloning and sequencing of the alcohol dehydrogenase II gene from Zymomonas mobilis. J Bacteriol 1987;169:2591-7.

[16] Jarboe LR, Grabar TB, Yomano LP, Shanmugam KT, Ingram LO. Development of ethanologenic bacteria. Adv Biochem Eng Biotechnol 2007;108:237-61.

[17] Arfman N, Worrell V, Ingram LO. Use of the tac promoter and lac/a for the controlled expression of Zymomonas mobilis fermentative genes in Escherichia coli and Zymomonas mobilis. J Bacteriol 1992;174:7370-8.

[18] Schiel-Bengelsdorf B, Montoya J, Linder S, Dürre P. Butanol fermentation. Environ Technol 2013;34:1691-710.

[19] Zhang F, Rodriguez S, Keasling JD. Metabolic engineering of microbial pathways for advanced biofuels production. Curr Opin Biotechnol 2011;22:775-83. 
1 [20] Xue C, Zhao XQ, Liu CG, Chen LJ, Bai FW. Prospective and development of butanol as an advanced biofuel. Biotechnol Adv 2013;31:1575-84.

3 [21] Choi YJ, Lee SY. Microbial production of short-chain alkanes. Nature 2013;502:571-4.

4 [22] Dunlop MJ. Engineering microbes for tolerance to next-generation biofuels. Biotechnol 5

[25] Taylor MP, Mulako I, Tuffin M, Cowan D. Understanding physiological responses to pretreatment inhibitors in ethanologenic fermentations. Biotechnol J 2012;7:1169-81.

[26] Nicolaou SA, Gaida SM, Papoutsakis ET. A comparative view of metabolite and substrate stress and tolerance in microbial bioprocessing: from biofuels and chemicals, to biocatalysis and bioremediation. Metab Eng 2010;12:307-31.

[27] Zingaro KA, Papoutsakis ET. Toward a semisynthetic stress response system to engineer microbial solvent tolerance. mBio 2012;3:E00308-12.

[28] Liu S, Qureshi N. How microbes tolerate ethanol and butanol. New Biotechnol 2009;26:117-21.

[29] Ramos JL, Duque E, Gallegos MT, Godoy P, Ramos-González MI, Rojas A, et al. Mechanisms of solvent tolerance in Gram-negative bacteria. Annu Rev Microbiol 2002;56:743-68.

[30] Ingram LO, Buttke TM. Effects of alcohols on micro-organisms. Adv Microb Physiol 1984;25:253-300.

[31] Ingram LO. Ethanol tolerance in bacteria. Crit Rev Biotechnol 1990;9:305-19.

[32] Pérez-Pantoja D, Nikel PI, Chavarría M, de Lorenzo V. Endogenous stress caused by faulty oxidation reactions fosters evolution of 2,4-dinitrotoluene-degrading bacteria. PLoS Genet 2013;9:e1003764.

[33] Martins dos Santos VAP, Heim S, Moore ER, Strätz M, Timmis KN. Insights into the genomic basis of niche specificity of Pseudomonas putida KT2440. Environ Microbiol 2004;6:1264-86. 
1 [34] Nikel PI. A brief guide to Pseudomonas putida as a microbial cell factory. BioEssays 2012; Available on line at http://goo.gl/DXF1y.

[35] Poblete-Castro I, Becker J, Dohnt K, Martins dos Santos VAP, Wittmann C. Industrial biotechnology of Pseudomonas putida and related species. Appl Microbiol Biotechnol 2012;93:2279-90.

[36] Abril MA, Michan C, Timmis KN, Ramos JL. Regulator and enzyme specificities of the TOL plasmid-encoded upper pathway for degradation of aromatic hydrocarbons and expansion of the substrate range of the pathway. J Bacteriol 1989;171:6782-90.

[37] Nikel PI, de Lorenzo V. Engineering an anaerobic metabolic regime in Pseudomonas putida KT2440 for the anoxic biodegradation of 1,3-dichloroprop-1-ene. Metab Eng 2013;15:98-112.

[38] de Lorenzo V, Timmis KN. Analysis and construction of stable phenotypes in gramnegative bacteria with Tn5- and Tn10-derived minitransposons. Methods Enzymol 1994;235:386-405.

[39] Chin WC, Lin KH, Chang JJ, Huang CC. Improvement of $n$-butanol tolerance in Escherichia coli by membrane-targeted tilapia metallothionein. Biotechnol Biofuels 2013;6:130.

[40] Rutherford BJ, Dahl RH, Price RE, Szmidt HL, Benke PI, Mukhopadhyay A, et al. Functional genomic study of exogenous $n$-butanol stress in Escherichia coli. Appl Environ Microbiol 2010;76:1935-45.

[41] Bradford MM. A rapid and sensitive method for the quantitation of microgram quantities of protein utilizing the principle of protein-dye binding. Anal Biochem 1976;72:248-54.

[42] Hoppner TC, Doelle HW. Purification and kinetic characteristics of pyruvate decarboxylase and ethanol dehydrogenase from Zymomonas mobilis in relation to ethanol production. Appl Microbiol Biotechnol 1983;17:152-7.

[43] Diefenbach RJ, Duggleby RG. Pyruvate decarboxylase from Zymomonas mobilis. Structure and re-activation of apoenzyme by the cofactors thiamin diphosphate and magnesium ion. Biochem J 1991;276:439-45.

[44] Neale AD, Scopes RK, Kelly JM, Wettenhall REH. The two alcohol dehydrogenases of Zymomonas mobilis. Purification by differential dye ligand chromatography, molecular characterisation and physiological roles. Eur J Biochem 1986;154:119-24. 
1 [45] Clark DP. The fermentation pathways of Escherichia coli. FEMS Microbiol Rev 1989;5:2232 34.

3 [46] Murarka A, Clomburg JM, Moran S, Shanks JV, Gonzalez R. Metabolic analysis of wildtype Escherichia coli and a pyruvate dehydrogenase complex (PDHc)-deficient derivative reveals the role of PDHc in the fermentative metabolism of glucose. J Biol Chem 2010;285:31548-58.

[47] Nikel PI, Ramirez MC, Pettinari MJ, Méndez BS, Galvagno MA. Ethanol synthesis from glycerol by Escherichia coli redox mutants expressing adhE from Leuconostoc mesenteroides. J Appl Microbiol 2010;109:492-504.

[48] Chavarría M, Nikel PI, Pérez-Pantoja D, de Lorenzo V. The Entner-Doudoroff pathway empowers Pseudomonas putida KT2440 with a high tolerance to oxidative stress. Environ Microbiol 2013;15:1772-85.

[49] del Castillo T, Ramos JL, Rodríguez-Herva JJ, Fuhrer T, Sauer U, Duque E. Convergent peripheral pathways catalyze initial glucose catabolism in Pseudomonas putida: genomic and flux analysis. J Bacteriol 2007;189:5142-52.

[50] Fuhrer T, Fischer E, Sauer U. Experimental identification and quantification of glucose metabolism in seven bacterial species. J Bacteriol 2005;187:1581-90.

[51] Rogers PL, Jeon YJ, Lee KJ, Lawford HG. Zymomonas mobilis for fuel ethanol and higher value products. Adv Biochem Eng Biotechnol 2007;108:263-88.

[52] Nielsen J, Larsson C, van Maris A, Pronk J. Metabolic engineering of yeast for production of fuels and chemicals. Curr Opin Biotechnol 2013;24:398-404.

[53] de Lorenzo V, Eltis L, Kessler B, Timmis KN. Analysis of Pseudomonas gene products using lacla/Ptrp-lac plasmids and transposons that confer conditional phenotypes. Gene 1993;123:17-24.

[54] Nikel PI, de Lorenzo V. Implantation of unmarked regulatory and metabolic modules in Gram-negative bacteria with specialised mini-transposon delivery vectors. J Biotechnol 2013;163:143-54.

[55] Díaz-Ricci JC, Tsu M, Bailey JE. Influence of expression of the pet operon on intracellular metabolic fluxes of Escherichia coli. Biotechnol Bioeng 1992;39:59-65. 
1 [56] Atsumi S, Wu TY, Machado IM, Huang WC, Chen PY, Pellegrini M, et al. Evolution, genomic analysis, and reconstruction of isobutanol tolerance in Escherichia coli. Mol Syst Biol 2010;6:449.

[57] Woodruff LB, Pandhal J, Ow SY, Karimpour-Fard A, Weiss SJ, Wright PC, et al. Genomescale identification and characterization of ethanol tolerance genes in Escherichia coli. Metab Eng 2013;15:124-33.

[58] Kang A, Tan MH, Ling H, Chang MW. Systems-level characterization and engineering of oxidative stress tolerance in Escherichia coli under anaerobic conditions. Mol Biosyst 2013;9:285-95.

[59] Unden G, Bongaerts J. Alternative respiratory pathways of Escherichia coli: energetics and transcriptional regulation in response to electron acceptors. Biochim Biophys Acta 1997;1320:217-34.

[60] Leonardo MR, Dailly Y, Clark DP. Role of NAD in regulating the adhE gene of Escherichia coli. J Bacteriol 1996;178:6013-8.

[61] Nelson KE, Weinel C, Paulsen IT, Dodson RJ, Hilbert H, Martins dos Santos VAP, et al. Complete genome sequence and comparative analysis of the metabolically versatile Pseudomonas putida KT2440. Environ Microbiol 2002;4:799-808.

[62] Winsor GL, Lam DKW, Fleming L, Lo R, Whiteside MD, Yu NY, et al. Pseudomonas Genome Database: improved comparative analysis and population genomics capability for Pseudomonas genomes. Nucleic Acids Res 2011;39:D596-D600.

[63] Nikel PI, Pettinari MJ, Galvagno MA, Méndez BS. Metabolic selective pressure stabilizes plasmids carrying biosynthetic genes for reduced biochemicals in Escherichia coli redox mutants. Appl Microbiol Biotechnol 2010;88:563-73.

[64] Nikel PI, Pérez-Pantoja D, de Lorenzo V. Why are chlorinated pollutants so difficult to degrade aerobically? Redox stress limits 1,3-dichloroprop-1-ene metabolism by Pseudomonas pavonaceae. Philos Trans R Soc Lond B Biol Sci 2013;368:20120377.

[65] Domínguez-Cuevas P, González-Pastor JE, Marqués S, Ramos JL, de Lorenzo V. Transcriptional tradeoff between metabolic and stress-response programs in Pseudomonas putida KT2440 cells exposed to toluene. J Biol Chem 2006;281:11981-91.

[66] Hanahan D, Meselson M. Plasmid screening at high colony density. Methods Enzymol 1983;100:333-42. 
1 [67] Herrero M, de Lorenzo V, Timmis KN. Transposon vectors containing non-antibiotic resistance selection markers for cloning and stable chromosomal insertion of foreign genes in Gram-negative bacteria. J Bacteriol 1990;172:6557-67.

4 [68] Boyer HW, Roulland-Dussoix D. A complementation analysis of the restriction and modification of DNA in Escherichia coli. J Mol Biol 1969;41:459-72.

6 [69] Baba T, Ara T, Hasegawa M, Takai Y, Okumura Y, Baba M, et al. Construction of 


\section{TABLES}

2

3 TABLE 1. Bacterial strains and plasmids used in this study.

4

\begin{tabular}{|c|c|c|}
\hline $\begin{array}{l}\text { Bacterial strain or } \\
\text { plasmid }\end{array}$ & Relevant characteristics ${ }^{a}$ & Reference \\
\hline \multicolumn{3}{|l|}{ E. coli } \\
\hline $\mathrm{DH} 5 \alpha$ & 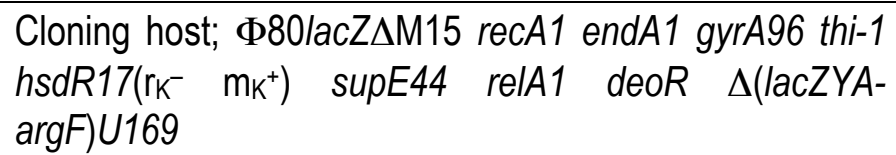 & [66] \\
\hline CC118גpir & $\begin{array}{l}\text { Cloning host; araD139 } \Delta(\text { ara-leu)7697 } \Delta \text { lacX74 galE } \\
\text { galK phoA20 thi-1 rpsE rpoB(RifR) } \arg E(\text { Am) } \operatorname{recA} 1, \lambda \text { pir } \\
\text { lysogen }\end{array}$ & [67] \\
\hline HB101 & 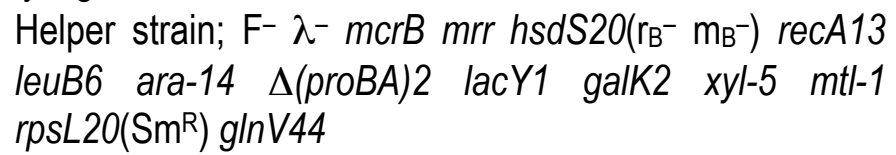 & [68] \\
\hline BW25113b & $\begin{array}{l}\text { Considered wild type in this study; } F^{-} \lambda^{-} \Delta(a r a D- \\
\text { araB)567 } \Delta \text { lacZ4787(::rrnB-3) rph-1 } \Delta(\text { rhaD-rhaB) } 568 \\
\text { hsdR514 }\end{array}$ & [69] \\
\hline \multicolumn{3}{|c|}{ Pseudomonas putida } \\
\hline KT2440 & $\begin{array}{l}\text { Considered wild type in this study; spontaneous } \\
\text { restriction-deficient derivative of strain mt-2 cured of the } \\
\text { TOL plasmid pWW0 }\end{array}$ & [70] \\
\hline \multicolumn{3}{|l|}{ Plasmid } \\
\hline pRK600 & $\begin{array}{l}\text { Helper plasmid used in tri-parental matings; oriV(ColE1) } \\
\text { RK2 tra+ } \mathrm{mob}^{+}, \mathrm{Cm}^{\mathrm{R}}\end{array}$ & [71] \\
\hline pSEVA234c & Expression vector; oriV(pBBR1) lac/Q $P_{\operatorname{trc}}$ aphA, $\mathrm{Km}^{\mathrm{R}}$ & [72] \\
\hline pS234ET & $\begin{array}{l}\text { Same as pSEVA234, carrying } p d c \text { and } a d h B \text { from } \\
\text { Zymomonas mobilis as single transcriptional unit; } \mathrm{Km}^{\mathrm{R}}\end{array}$ & [37] \\
\hline
\end{tabular}

5

6 a Antibiotic resistance markers: Cm, chloramphenicol; Km, kanamycin; Rif, rifampicin; Sm,

7 streptomycin.

8 b Strain obtained from the E. coli Genetic Stock Center (Yale University, New Haven, CT, USA).

9 c Plasmid belonging to the SEVA (Standard European Vector Architecture) collection. 
1 TABLE 2. Pattern of fermentation metabolites after $24 \mathrm{~h}$ of anoxic incubationa.

2

\begin{tabular}{llcccc}
\hline \multirow{2}{*}{ Bacterial strain } & \multirow{2}{*}{ Plasmid } & \multicolumn{4}{c}{ Metabolite concn. ${ }^{\mathrm{b}}(\mathrm{mM})$} \\
\cline { 3 - 6 } & & Acetate & Lactate & Formate & Succinate \\
\hline \multirow{2}{*}{ E. coli BW25113 } & pSEVA234 & $68.1 \pm 6.3$ & $6.5 \pm 0.9$ & $27.8 \pm 9.3$ & $12.3 \pm 1.8$ \\
& pS234ET & $46.9 \pm 3.7$ & $4.2 \pm 0.8$ & $24.9 \pm 5.4$ & $8.4 \pm 0.9$ \\
\hline P. putida KT2440 & pSEVA234 & $<1.5$ & - & - & - \\
& pS234ET & $<0.5$ & - & - & - \\
\hline
\end{tabular}

3

4 a Culture conditions were as described for Fig. 2, and the samples used to quantify EtOH were 5 also processed to detect fermentation acids.

6 b Results correspond to mean values \pm standard deviations of triplicate measurements from at 7 least two independent experiments; concn., concentration; -, not detected.

8 
1 TABLE 3. Enzymatic activities of the heterologous EtOH synthesis pathway in the presence 2 of exogenously added alcohola.

3

\begin{tabular}{lccc}
\hline \multirow{2}{*}{ Bacterial host } & $\begin{array}{c}\text { EtOH concn.c } \\
(\% \mathrm{v} / \mathrm{v})\end{array}$ & \multicolumn{2}{c}{ Sp. enzymatic activity $\left(\mu \mathrm{mol} \mathrm{min}^{-1} \mathrm{mg} \mathrm{protein}^{-1}\right)$ for: } \\
\cline { 3 - 4 } & 0 & Pyruvate decarboxylase & Alcohol dehydrogenase \\
\hline E. coli BW25113 & 1 & $5.4 \pm 0.9$ & $2.1 \pm 0.7$ \\
& 5 & $3.7 \pm 0.5$ & $1.4 \pm 0.2$ \\
\hline P. putida KT2440 & 0 & $1.1 \pm 0.2$ & $0.8 \pm 0.1$ \\
& 1 & $4.9 \pm 0.8$ & $2.9 \pm 0.3$ \\
& 5 & $5.2 \pm 0.5$ & $2.7 \pm 0.5$ \\
\hline
\end{tabular}

4

5 a Culture conditions were as described for Fig. 2. Both bacterial hosts were transformed with $6 \quad$ pS234ET (carrying $p d c-a d h B^{Z}$. mobilis).

7 b Note that low concentrations of alcohol were still detected in experiments with no externally

8 added ethanol, as detailed in Fig. 2C. Concn., concentration.

9 c Pyruvate decarboxylase was not detected in cells transformed with the empty pSEVA234

10 vector; alcohol dehydrogenase activity was corrected by the background activity determined in 11 such control experiments. Results correspond to mean values \pm standard deviations of triplicate

12 measurements from at least two independent experiments; Sp., specific. 
3 FIG. 1. Simplified scheme of the pathways involved in glucose catabolism.

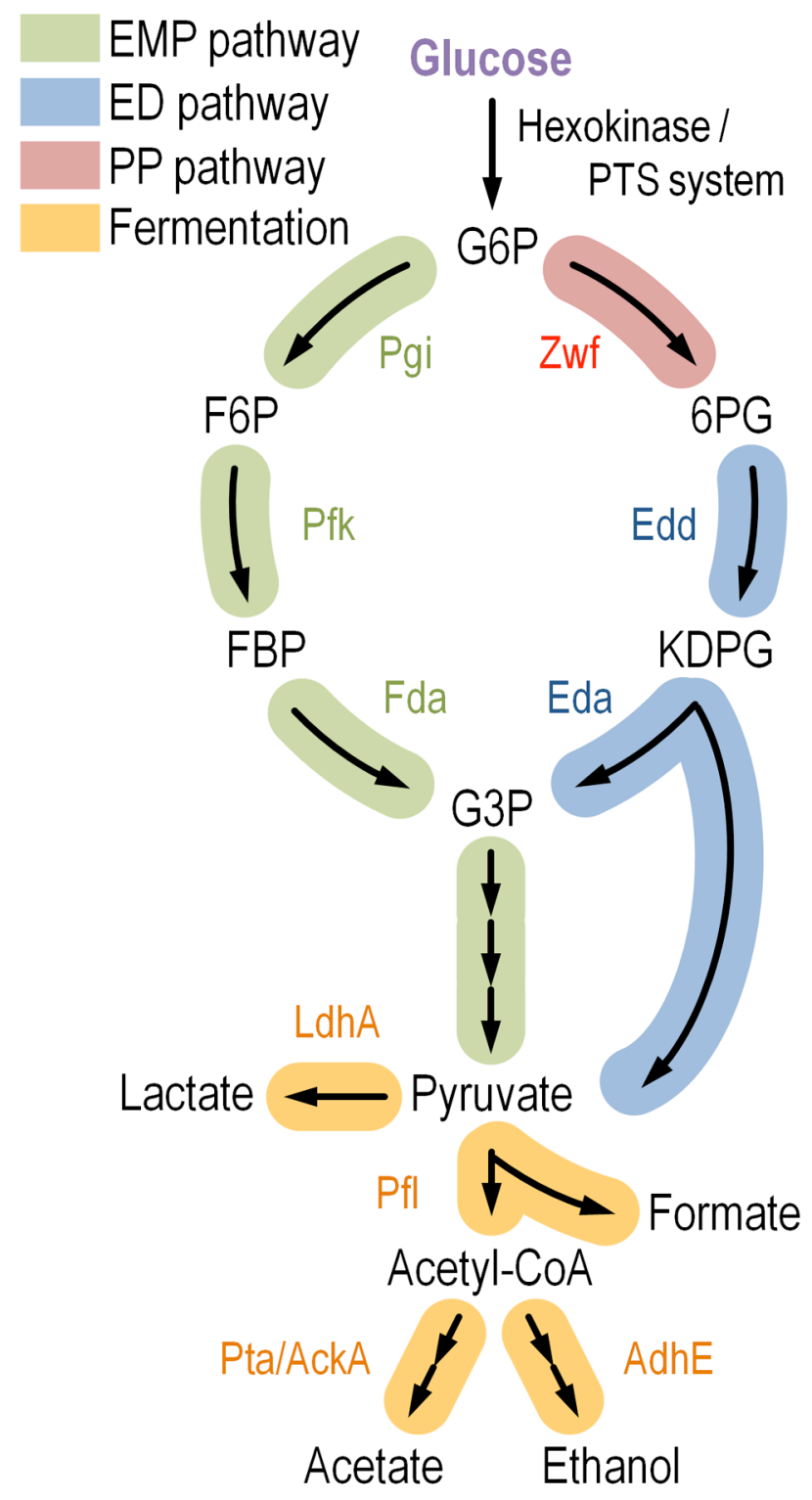

7 After an initial phosphorylation step, catalyzed either by an hexokinase or the phosphotransferase

8 (PTS) system, the resulting glucose-6-P (G6P) can either (i) follow the Embden-Meyerhof-Parnas

9 (EMP) route [via the sequential conversion of G6P into fructose-6-P (F6P) and fructose-1,6- $P_{2}$

10 (FBP)], or (ii) be channeled through the Entner-Doudoroff (ED) route [via the transformation of 11 G6P into 6-P-gluconate (6PG) and 2-keto-3-deoxy-6-P-gluconate (KDPG)]. Note that both 12 pathways finally yield glyceraldehyde-3-P (G3P) and pyruvate. The oxidative pentose phosphate 13 (PP) pathway is not shown in the outline. While Escherichia coli mostly uses the EMP pathway for 
1 glucose breakdown, Pseudomonas putida exclusively processes the hexose via the ED pathway.

2 Under oxic conditions, pyruvate is transformed into acetyl-coenzyme $A(C O A)$ in both

3 microorganisms through the activity of the pyruvate dehydrogenase complex in a NAD+-

4 dependent reaction. Although acetyl-CoA can meet different fates depending on further catabolic 5 steps, it is mainly oxidized in the tricarboxylic acid cycle. Under anoxic conditions, E. coli

6 produces a number of fermentation metabolites from pyruvate or acetyl-CoA to meet the carbon

7 and redox balances. While some genes encoding putative fermentation enzymes are present in

8 P. putida, this microorganism does not ferment glucose in the absence of oxygen. The main

9 metabolic blocks are depicted in different colors, and the relevant enzymatic steps are identified.

10 The arrows connecting G3P and pyruvate represent several metabolic steps. Redundant 11 enzymes, branched pathways conducive to the same intermediates, co-factor dependence, and 12 multi-step transformations are not shown in this outline. Enzyme abbreviations are termed as 13 follows: Pgi, phosphoglucoisomerase; Zwf, G6P dehydrogenase; Pfk, phosphofructokinase; Fda, 14 FBP aldolase; Edd, 6PG dehydratase; Eda, KDGP aldolase; Pfl, pyruvate-formate lyase; LdhA, 15 D-lactate dehydrogenase; Pta, phosphotransacetylase; AckA, acetate kinase; and AdhE, alcohol 16 dehydrogenase. 
1 FIG. 2. Design of an ethanol (EtOH) synthesis pathway composed of enzymes recruited from 2 Zymomonas mobilis.
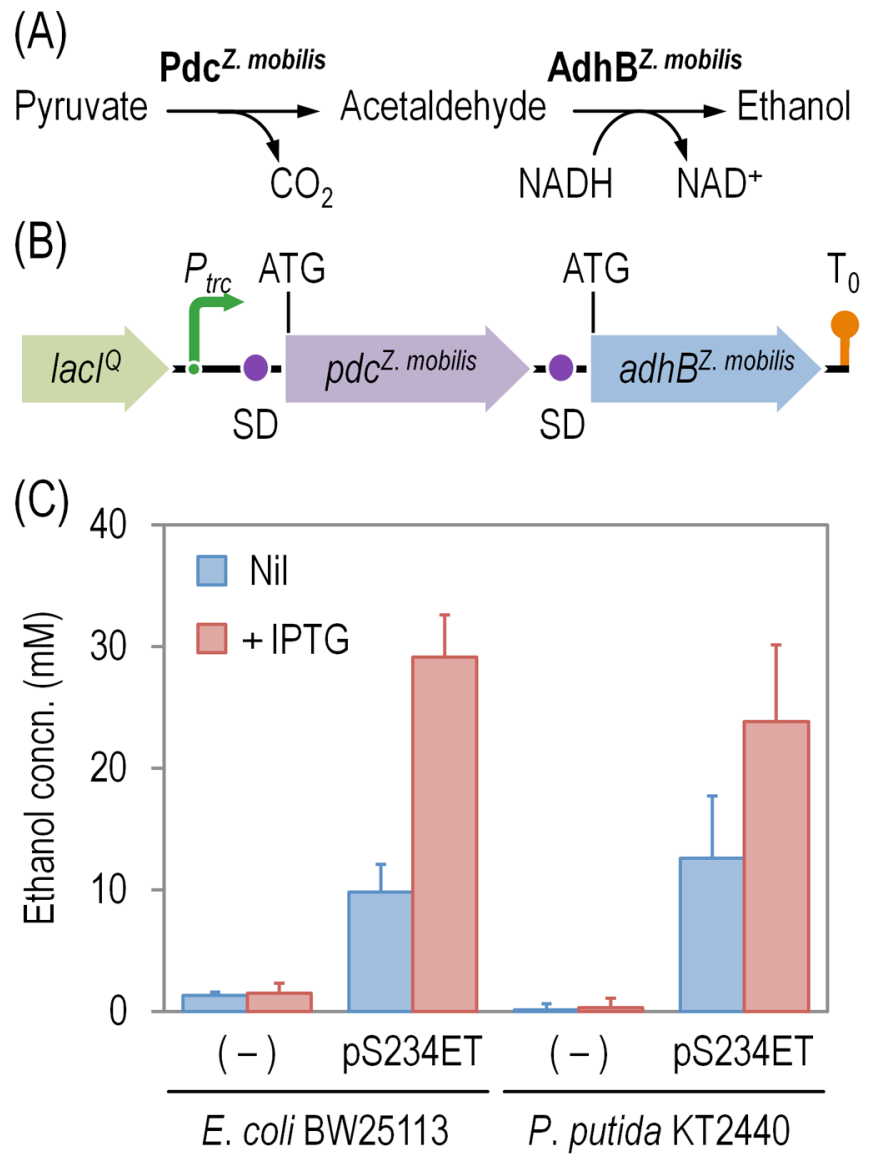

6 (A) Pyruvate, generated from glucose either via the Embden-Meyerhof-Parnas pathway (in 7 Escherichia coli) or via the Entner-Doudoroff pathway (in Pseudomonas putida), is 8 decarboxylated to acetaldehyde by pyruvate decarboxylase ( $\mathrm{Pdc}^{\mathrm{Z}}$. mobilis). Acetaldehyde is then 9 converted into $\mathrm{EtOH}$ by means of alcohol dehydrogenase II (AdhBZ. mobilis), together with the concomitant oxidation of one NADH molecule. (B) Schematic representation of the synthetic operon in which $p d c^{Z}$. mobilis and $a d h B^{Z}$. mobilis are placed under the control of an inducible LaclQ/P $P_{\text {trc }}$ element as a single transcriptional unit, borne by plasmid pS234ET. Each coding sequence was preceded with a Shine-Dalgarno (SD) motif, and the stop codons were edited to TAA. The transcriptional terminator of the bacteriophage $\lambda$ is depicted as $T_{0}$. The elements in this outline are not drawn to scale. (C) Quantification of the EtOH concentration (concn.) in culture medium supernatants. Cells from oxic mid-exponential cultures were spun, washed, concentrated, and transferred to fresh culture medium $\left(\mathrm{OD}_{600} \mathrm{ca}\right.$. 2) containing $20 \mathrm{~g} \mathrm{l}^{-1}$ glucose and with or without $2.5 \mathrm{mM}$ IPTG. These cultures were incubated under anoxic conditions for $24 \mathrm{~h}$ before samples were taken to analyze $\mathrm{EtOH}$ formation. Control experiments (-) were carried out using either $E$. coli BW25113 or P. putida KT2440 bearing the empty vector (pSEVA234). Bars represent the mean value of the EtOH concn. \pm standard deviation of triplicate measurements from at least two independent experiments. 
1 FIG. 3. Evaluation of time-dependent cell survival, ethanol (EtOH) formation, and ROS levels.

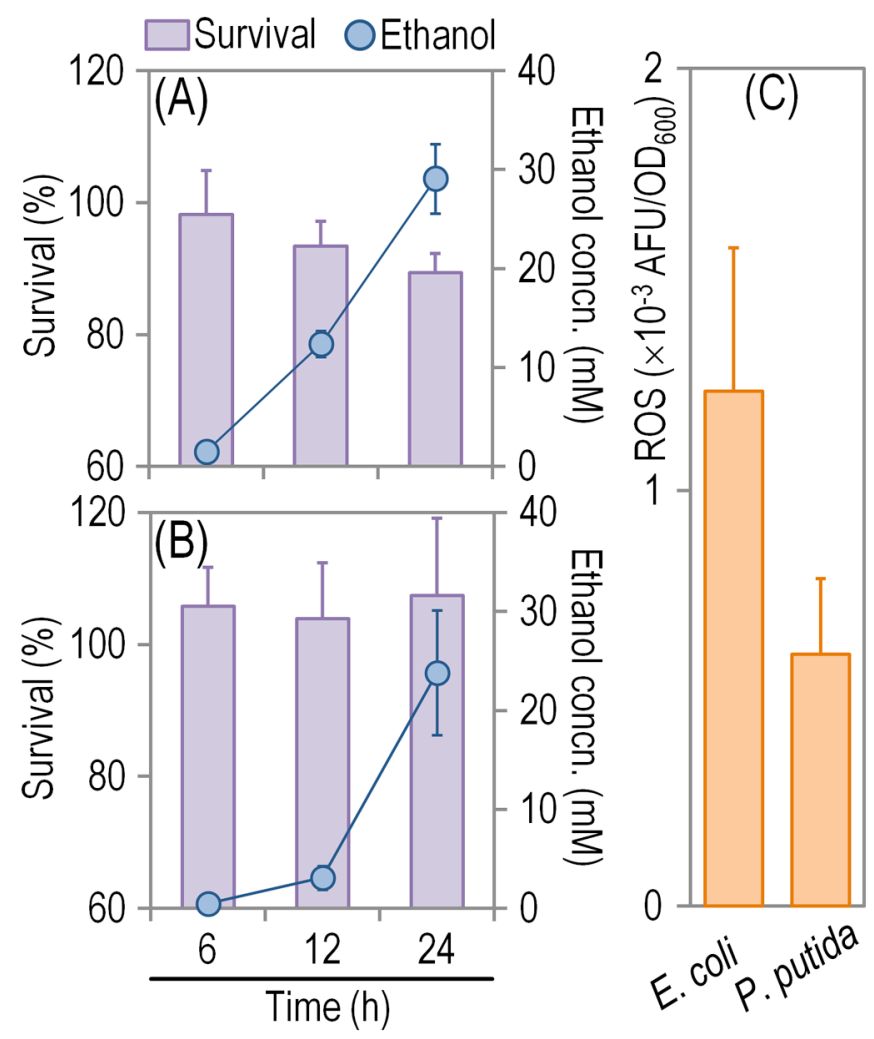

$5 \quad$ These parameters were determined in cell suspensions of (A) E. coli BW25113/pS234ET and (B)

$6 \quad P$. putida KT2440/pS234ET incubated anoxically. Survival was assessed by plating appropriately 7 diluted culture aliquots into fresh LB plates and incubating them for 18 to $24 \mathrm{~h}$ (survival percentages are referred to CFUs counts of the corresponding strain transformed with the empty pSEVA234 vector, and evaluated at the same anoxic incubation time as the ethanologenic recombinants). EtOH concentration (concn.) was determined in the supernatant of the same culture samples. Culture conditions were as indicated for Fig. 1. The levels of ROS produced by endogenous EtOH were estimated in vivo (C) by exposing the cells transformed with pS234ET to carboxy- $\mathrm{H}_{2} \mathrm{DCFDA}$, and measuring the fluorescence resulting from the ROS-dependent oxidation of the probe (AFU, arbitrary florescence units) followed by normalization by the biomass used in each assay [estimated as the optical density measured at $\left.600 \mathrm{~nm}\left(\mathrm{OD}_{600}\right)\right]$. Bars and data points represent the mean value of the corresponding parameter \pm standard deviation of triplicate or quadruplicate measurements from at least two independent experiments. 
1 FIG. 4. Survival of ethanologens in the presence of exogenous ethanol (EtOH).

2

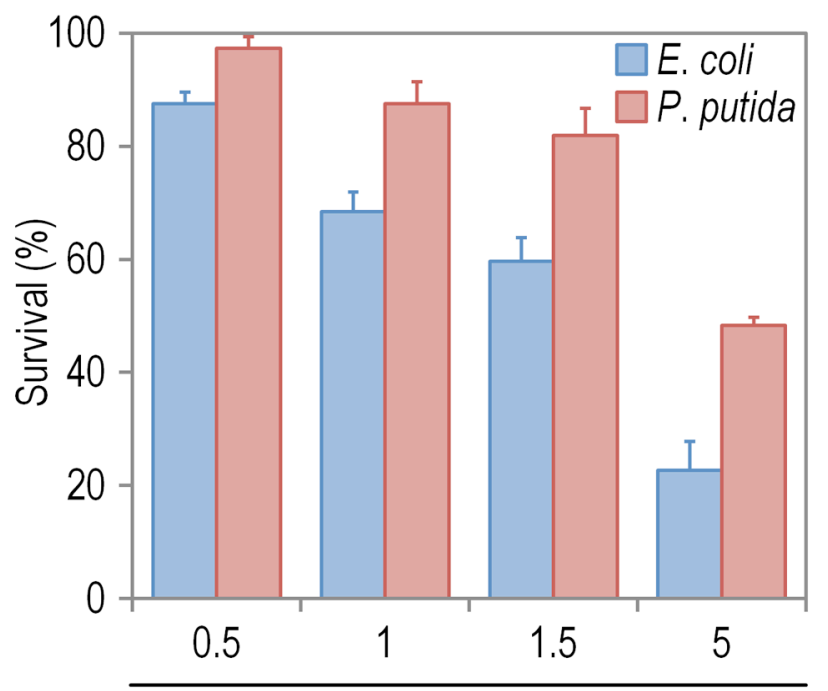

3

Ethanol concn. $(\% \mathrm{v} / \mathrm{v})$

4

5 Survival was assessed by plating appropriately diluted culture aliquots into fresh LB plates and

6 incubating them for 18 to $24 \mathrm{~h}$ (survival percentages are referred to CFUs counts of the 7 corresponding strain transformed with the empty pSEVA234 vector, and evaluated at the same 8 anoxic incubation time without any added alcohol as the ethanologenic recombinants). EtOH 9 concentration (concn.) is indicated in each case. Bars represent the mean value of the survival 10 score \pm standard deviation of triplicate measurements from at least two independent 11 experiments. 
1 FIG. 5. Quantification of the ROS levels produced by exogenous ethanol (EtOH).

2
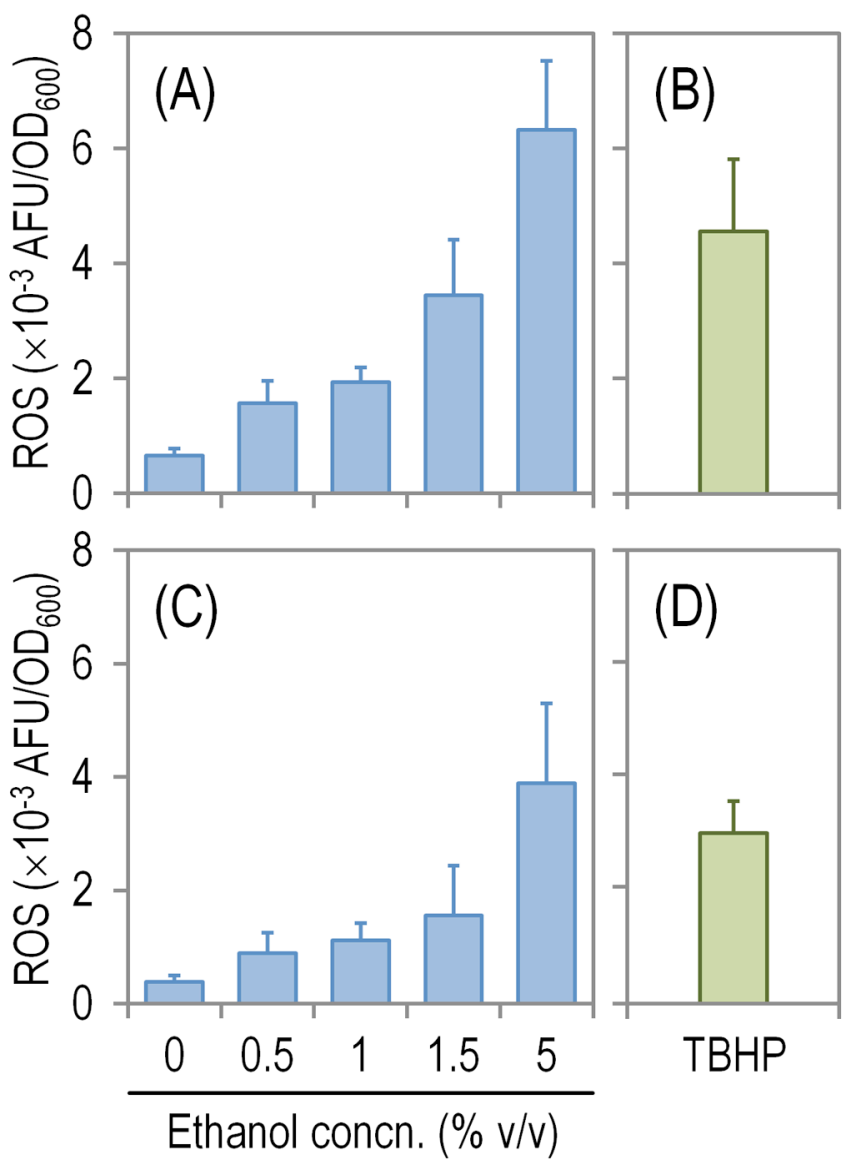

5 ROS formation was estimated in vivo by exposing the cells transformed with pS234ET to different 6 concentrations (concn.) of ethanol, followed by staining with carboxy- $\mathrm{H}_{2}$ DCFDA. The 7 fluorescence resulting from the ROS-dependent oxidation of the probe (AFU, arbitrary 8 florescence units) was quantified and normalized by the biomass used in each assay [estimated 9 as the optical density measured at $\left.600 \mathrm{~nm}\left(\mathrm{OD}_{600}\right)\right]$. Note that low alcohol concn. were detected

10 in experiments with no externally added ethanol, as detailed in Fig. 2C. Positive control 11 experiments were added with tert-butyl hydroperoxide (TBHP). Bars represent the mean value of 12 the ROS level \pm standard deviation of quadruplicate measurements from at least two 13 independent experiments. 
$1 \quad$ FIG. 6. Phenotypic stability of the recombinants.

2

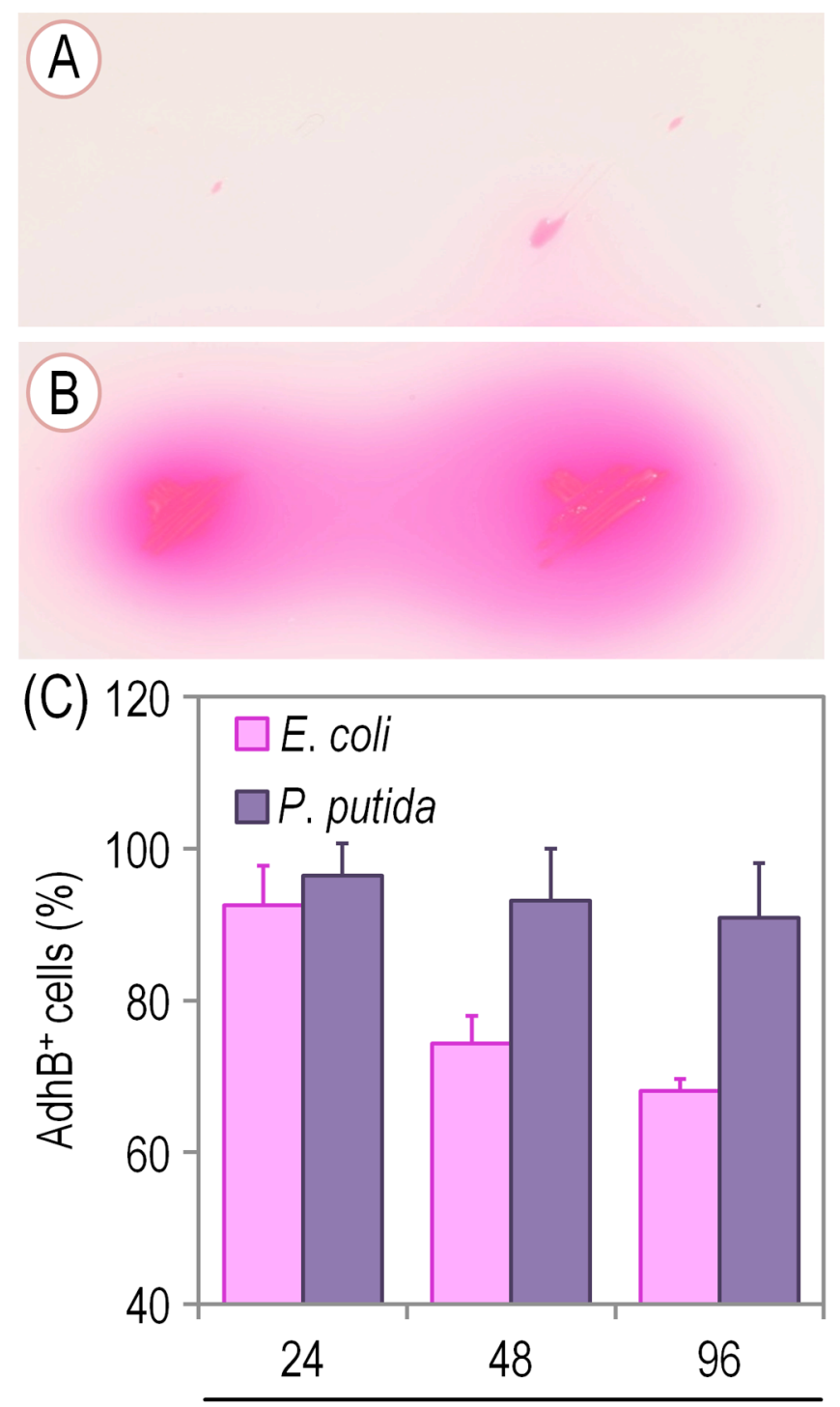

5 The ability of either E. coli BW25113/pS234ET or P. putida KT2440/pS234ET to retain the AdhB ${ }^{+}$ 6 phenotype was evaluated after $24 \mathrm{~h}, 48 \mathrm{~h}$, and $96 \mathrm{~h}$ of anoxic incubation via an in vivo test using 7 aldehyde indicator plates. Cells were spread onto these plates and incubated for 4-6 h, after 8 which colonies were scored and those exhibiting a magenta coloration were considered positive 9 (Adh $\left.B^{+}\right)$. Qualitative results of the test are shown for selected (A) E. coli and (B) P. putida 10 recombinants after $48 \mathrm{~h}$ (left) and $96 \mathrm{~h}$ (right) anoxic incubations. (C) Quantification of the 11 phenotypic stability in the ethanologens. Bars represent the mean value of the percentage of $12 \mathrm{AdhB}^{+}$clones \pm standard deviation of duplicate measurements from at least three independent experiments. 